\title{
Seeds of native alpine plants host unique microbial communities embedded in cross- kingdom networks
}

\author{
Birgit Wassermann', Tomislav Cernava ${ }^{1}$, Henry Müller ${ }^{1}$, Christian Berg ${ }^{2}$ and Gabriele Berg ${ }^{1 *}$ (D)
}

\begin{abstract}
Background: The plant microbiota is crucial for plant health and growth. Recently, vertical transmission of a beneficial core microbiota was identified for crop seeds, but for native plants, complementary mechanisms are almost completely unknown.

Methods: We studied the seeds of eight native plant species growing together for centuries under the same environmental conditions in Alpine meadows (Austria) by qPCR, FISH-CLSM, and amplicon sequencing targeting bacteria, archaea, and fungi.

Results: Bacteria and fungi were determined with approx. $10^{10}$ gene copy numbers $\mathrm{g}^{-1}$ seed as abundant inhabitants. Archaea, which were newly discovered as seed endophytes, are less and represent only $1.1 \%$ of the signatures. The seed microbiome was highly diversified, and all seeds showed a species-specific, highly unique microbial signature, sharing an exceptionally small core microbiome. The plant genotype (species) was clearly identified as the main driver, while different life cycles (annual/perennial) had less impact on the microbiota composition, and fruit morphology (capsule/achene) had no significant impact. A network analysis revealed significant co-occurrence patterns for bacteria and archaea, contrasting with an independent fungal network that was dominated by mutual exclusions.

Conclusions: These novel insights into the native seed microbiome contribute to a deeper understanding of seed microbial diversity and phytopathological processes for plant health, and beyond that for ecosystem plasticity and diversification within plant-specific microbiota.
\end{abstract}

Keywords: Seed microbiota, native plants, cross-kingdom networks, endophytes, plant resilience

\section{Background}

Plants and their associated microbes have been interacting with each other for a long time, forming an assemblage of species that is often referred to as a holobiont [1]. The plant microbiome is essential for plant development, resilience, and health [2]. Endophytic communities represent an intimate core of the plant microbiota and connect different plant microhabitats, with specific roles during development stages that are important for health issues [3]. The rhizosphere is a reservoir for plant endophytes and represents the below-ground interface with

\footnotetext{
* Correspondence: gabriele.berg@tugraz.at

${ }^{1}$ Institute of Environmental Biotechnology, Graz University of Technology,

Petersgasse 12, 8010 Graz, Austria

Full list of author information is available at the end of the article
}

the highly diverse soil microbiota [4]. For a long time, it was assumed that the emerging seedling is colonized by microbes from its surrounding environment, with soil being the main source and plant-controlled enrichment through different strategies, such as the specific profile of root exudates and its immune system [5-7]. Therefore, studies related to the seed microbiota have often been neglected or focused only on the presence of pathogens [8]; there are less comprehensive studies including all components of the microbiome [9]. In the past, only a few studies on seed-derived bacteria were published, because they are difficult to cultivate, while seed-borne archaea were not identified at all so far $[10,11]$. Our knowledge related to seed fungi is much broader as reviewed by Geisen et al. [12] and Yang et al. [13], especially

(c) The Author(s). 2019 Open Access This article is distributed under the terms of the Creative Commons Attribution 4.0 International License (http://creativecommons.org/licenses/by/4.0/), which permits unrestricted use, distribution, and 
in terms of information available on clavicipitaceous endophytes such as Epichloë/Neotyphodium species due to their beneficial and specific interaction with grasses, which is already commercially exploited $[14,15]$. However, we still need a complete picture of the seed microbiota and its interactions and functions in the holobiont.

Recently, crop seeds were discovered as a source to transmit a plant-specific core microbiota [16-18]. Studies focusing on the crop microbiome showed that domestication and intense agricultural management entailed alterations of the inherent microbiome of crop plants including a loss of plant-beneficial microbiota [19-21]. First results indicate similar effects on the seed microbiota $[16,22]$. Understanding the key components of the indigenous seed microbiota of native plants can support the definition of a healthy microbiota and its translation to our crops. So far, little is known about the indigenous seed microbiota in natural ecosystems [12]. Our hypothesis was that seeds of native plants harbor a specific and diverse microbiota, which allows plant populations to survive, persist, and germinate under harsh natural conditions $[23,24]$.

To decipher the entire seed microbiota of native plants, we selected healthy plant populations persisting over centuries in the European Eastern Alps. The Hochschwab region (Northern Calcareous Alps, Austria) is a glacial retreat for a high diversity of plant species and is botanically and geologically well-studied [25]. To identify the composition and main drivers (plant genotype, life cycle, fruit morphology) of the native seed microbiota, we selected eight different alpine plant species, all of which were traditionally used as medicinal plants and produce a variety of antimicrobial compounds [26, 27]. Although nothing is known about bioactive compounds in the seeds of the selected species, we expect that those phytochemicals have profound impacts on the seed microbiota. In addition, we hypothesize a strong impact of fruit morphology; here, we expected a higher microbial diversity for seeds of indehiscent fruits (achenes) than for seeds of dehiscent fruits (capsules). Achenes are monocarpellate structures, where the seeds are united with the pericarp forming a unit developed and distributed under the influence of the surrounding environment. A separation between seeds and fruit in achenes is not possible methodically, and we use the term seeds in the following text including achenes. Capsules are enclosed systems, where seeds develop inside, covered by the pericarp that splits apart to extrude the seeds at maturity. In these structures, the surrounding environment has a lower impact on the seed microbiome. The selected plants are also characterized by a different life cycle (annuals/perennials). We hypothesize that perennials can accumulate a higher microbial diversity during their life cycle.

\section{Materials and methods}

\section{Experimental design and sampling procedure}

For the microbiome analyses, eight different alpine plant species (in the following referred to as plant genotypes) were selected according to different life cycles and fruit morphologies. Our selection comprised the following species: great masterwort Astrantia major L., Eyebright Euphrasia rostkoviana HAYNE, willow gentian Gentiana asclepiadea L., Chiltern gentian Gentianella germanica (WILlD.) E.F.WARB., Heliosperma quadrifida WALDST. \& KIT., bog star Parnassia palustris L., Yellow rattle Rhinanthus glacialis PERSONNAT, and pincushion flowers Scabiosa lucida VILL. These plant species differ in their fruit morphologies; E. rostkoviana, R. glacialis, G. germanica, $H$. quadrifida, P. palustris, and G. asclepiadea produce capsules as dehiscent fruits and S. lucida and $A$. major seeds produce achenes as indehiscent fruits. Plants can furthermore be distinguished by their life cycle, which is either annual (E. rostkoviana, $R$. glacialis, and G. germanica) or perennial (H. quadrifida, P. palustris, G. asclepiadea, S. lucida, and A. major). All seeds were collected at time of dispersal in maturation state. The sampling was performed on September 4, 2016, at the Aflenzer Staritzen (Longitude: E15.183899, Latitude: N47.622001) in an area of approximately $100,000 \mathrm{~m}^{2}$ in the Hochschwab region (Northern Calcareous Alps, Austria), which represent a botanically well-studied glacial retreat [25]. Each of the eight plant species was sampled from four different sites randomly selected across the total area. Each replicate consists of 15 to 20 plants that grew in close proximity (subpopulations). The distance between the replicates was $200 \mathrm{~m}$ in minimum. Seeds of plants from one subpopulation were handled under sterile conditions and subsequently pooled. From each pool, $50 \mathrm{mg}$ were weighted in, now referred to as one replicate, and total community DNA was extracted. We decided to use consistent seed weights for each replicate instead of seed counts due to strong variability in seed size and anatomy between the different plant genotypes (Fig. 1a).

\section{Microbial DNA extraction and amplicon library construction}

Seeds were physically disrupted under sterile conditions with liquid nitrogen, and the total community DNA was extracted using the FastDNA Spin Kit for Soil (MP Biomedicals, Solon, USA) and a FastPrep Instrument (MP Biomedicals, Illkirch, France) for $30 \mathrm{~s}$ at $5.0 \mathrm{~ms}^{-1}$. Illumina amplicon sequencing was performed by using two different barcoded primer combinations: 515f-806r [28] to amplify $16 \mathrm{~S}$ rRNA gene fragments and ITS1f-ITS2r [29] to amplify parts of the ITS region, with three technical replicates per sample. By adding peptide nucleic acid (PNA) clamps 


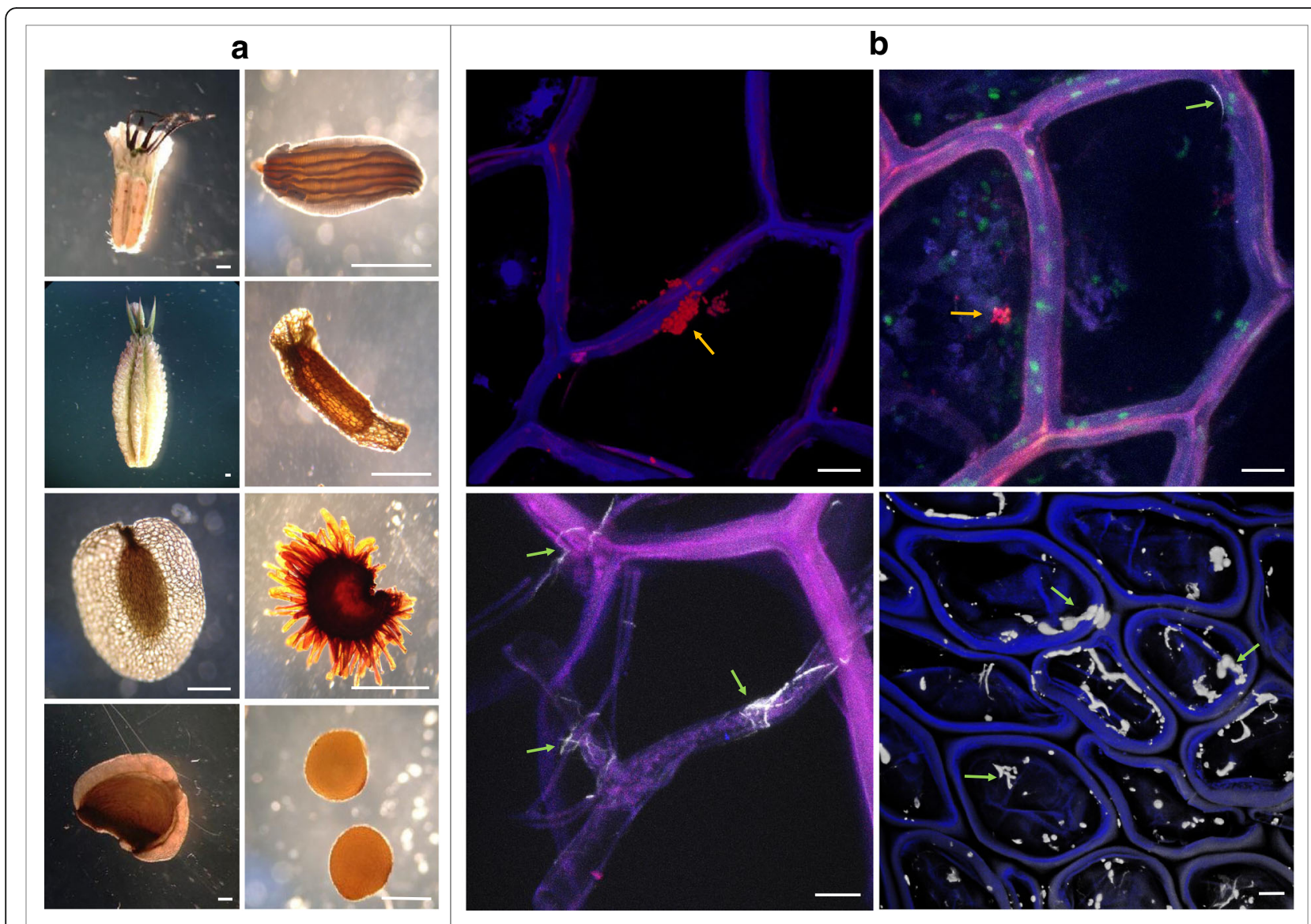

Fig. 1 Micrographs of alpine plant seeds (including achenes). a Whole seed visualization shows the high morphological diversity of the alpine plant seeds investigated, from left to right and top to bottom: S. lucida, E. rostkoviana, A. major, P. palustris, G. asclepiadea, H. quadrifida, R. glacialis, and G. germanica. Scale bars in a indicate $0.5 \mathrm{~mm}$. b FISH-Confocal laser scanning micrographs visualize endophytic fungi (indicated by green arrows) and bacteria (yellow arrows) in P. palustris and G. asclepiadea seeds. Scale bars in b indicate $10 \mu \mathrm{m}$

to the PCR mix, amplification of host plastid and mitochondrial 16S DNA was blocked [30]. PCR for $16 S$ rRNA gene amplification was performed in a total volume of $30 \mu \mathrm{l}$ (5 x Taq\&Go (MP Biomedicals, Illkirch, France), $1.5 \mu \mathrm{M}$ PNA mix, $0.25 \mathrm{mM}$ of each primer, PCR-grade water, and $1 \mu$ lemplate DNA) under the following cycling conditions: $95^{\circ} \mathrm{C}$ for $5 \mathrm{~min}, 30$ cycles of $96^{\circ} \mathrm{C}$ for $1 \mathrm{~min}, 78^{\circ} \mathrm{C}$ for $5 \mathrm{~s}, 54^{\circ} \mathrm{C}$ for $1 \mathrm{~min}$, $74{ }^{\circ} \mathrm{C}$ for $60 \mathrm{~s}$, and a final elongation at $74{ }^{\circ} \mathrm{C}$ for 10 min. Amplification of the fungal ITS region was conducted in $20 \mu \mathrm{l}\left(5 \mathrm{x}\right.$ Taq\&Go, $25 \mathrm{mM} \mathrm{MgCl}_{2}, 10 \mu \mathrm{M}$ of each primer, PCR-grade water, and $1 \mu \mathrm{l}$ template DNA) with the cycling conditions $95^{\circ} \mathrm{C}$ for $5 \mathrm{~min}, 30$ cycles of $94{ }^{\circ} \mathrm{C}$ for $30 \mathrm{~s}, 58^{\circ} \mathrm{C}$ for $35 \mathrm{~s}, 72^{\circ} \mathrm{C}$ for $40 \mathrm{~s}$, and final elongation at $72^{\circ} \mathrm{C}$ for $10 \mathrm{~min}$. A nested PCR step was performed to add barcoded primers. Technical replicates were combined and purified by Wizard SV Gel and PCR Clean-Up System (Promega, Madison, WI, USA), and DNA concentrations were measured with Nanodrop 2000 (Thermo Scientific, Wilmington, DE, USA). Samples were combined in equimolar concentration and sequenced by Illumina MiSeq v2 (250 bp paired-end) amplicon sequencing.

\section{Illumina MiSeq data processing of 16S rRNA gene and ITS region amplicons and statistics}

Raw sequence data preparation and data analysis was performed using QIIME 1.9.1 [28]. Paired reads were joined and quality filtered (phred q20), and chimeric sequences were identified using usearch7 [31] and removed. Operational taxonomic units (OTUs) were picked according to open references given by SILVA ver128_97_01.12.17 for 16S rRNA gene and UNITE ver7_99_01.12.17 for fungal ITS region. De novo clustering of OTUs was performed using usearch for bacterial and archaeal 16S rRNA and BLAST for fungal ITS region. Representative sequences were aligned, taxonomy was assigned, and sequences assigned to host mitochondria and chloroplasts were discarded. OTU tables were rarefied to the lowest number of read counts (1739 sequences for $16 \mathrm{~S}$ rRNA gene and 5807 sequences for ITS region). Bacterial and fungal core OTUs that were 
present in all alpine plant seeds investigated were further identified up to species level using NCBI BLAST alignment tool. Rarefied OTU tables served as input matrix for all upcoming alpha and beta diversity analyses. Statistics on microbial diversity and abundance were calculated in QIIME. Significant differences $(p<0.05)$ in Shannon diversity between groups for 16S rRNA gene fragments and for the ITS region were calculated based on parametric two-sample $t$ test at the greatest rarefaction depth using $t$ distribution to determine the $p$ value. Beta diversity, based on weighted UniFraq distance matrix for bacteria and Bray-Curtis dissimilarities for fungi, was assessed by principal coordinates analysis (PCoA), and the statistical significance between categorical variables was assessed by analysis of similarity (ANOSIM), including the pairwise option to compare differences between all plant genotypes. IBM SPSS program (version 25.0, IBM Corporation, Armonk, NY, USA) was used for calculating significant differences $(p<0.05)$ in microbial gene copy quantity, determined via quantitative $\mathrm{PCR}$, based on ANOVA including Tukey-HSD test correction. Cytoscape version 3.4.0 and the add-on "CoNet" were used to perform network analysis of significant $(q \geq 0.0004)$ co-occurrence and mutual exclusion patterns of the microbiomes. Combined fungal and bacterial OTU table, collapsed on species level using absolute abundances, served as input matrix for the cooccurrence network. To ensemble inferences, Pearson and Spearman correlation coefficients for both positive and negative correlations, using the automatic threshold setting for the 1000 top and bottom edges for each method, the mutual information option, and Bray-Curtis and Kullback-Leibler dissimilarity matrices were applied. For the final network, bootstrapping was selected as resampling method and Brown's method was used to merge method- and edge-specific $p$ values, discarding unstable edges that showed scores outside the 0.95\% range of their bootstrap distribution. The BenjaminiHochberg method was selected for multiple test correction.

\section{Quantitative real-time PCR}

For quantifying gene copy numbers of bacteria, archaea, and fungi within seeds, a quantitative real-time PCR (qPCR) was performed using the following primer pairs: $515 \mathrm{f}-927 \mathrm{r}$ for bacteria $(10 \mu \mathrm{M}$ each; [32]), 344aF-517uR for archaea $(5 \mu \mathrm{M}$ each; [33]), and ITS1-ITS2 for fungi $(10 \mu \mathrm{M}$ each; [29]). The reaction mix contained $5 \mu \mathrm{l}$ KAPA SYBR Green, $0.5 \mu \mathrm{l}$ of each primer, $3 \mu \mathrm{l}$ PCRgrade water, and $1 \mu \mathrm{l}$ template DNA (diluted 1:10 in PCR grade water). Fluorescence intensities were detected in a Rotor-Gene 6000 real-time rotary analyzer (Corbett Research, Sydney, Australia) with the following cycling conditions: bacteria: $95^{\circ} \mathrm{C}$ for $5 \mathrm{~min}, 40$ cycles of $95^{\circ} \mathrm{C}$ for $20 \mathrm{~s}, 54^{\circ} \mathrm{C}$ for $30 \mathrm{~s}, 72{ }^{\circ} \mathrm{C}$ for $30 \mathrm{~s}$, and a final melt curve of 72 to $96^{\circ} \mathrm{C}$; archaea: $95^{\circ} \mathrm{C}$ for $5 \mathrm{~min}, 40$ cycles of $95^{\circ} \mathrm{C}$ for $15 \mathrm{~s}, 60^{\circ} \mathrm{C}$ for $30 \mathrm{~s}, 72^{\circ} \mathrm{C}$ for $30 \mathrm{~s}$, followed by melt curve of 72 to $96^{\circ} \mathrm{C}$; fungi: $95^{\circ} \mathrm{C}$ for $5 \mathrm{~min}, 40$ cycles of $95^{\circ} \mathrm{C}$ for $30 \mathrm{~s}, 58^{\circ} \mathrm{C}$ for $35 \mathrm{~s}, 72^{\circ} \mathrm{C}$ for $40 \mathrm{~s}$ with a melt curve of 72 to $96^{\circ} \mathrm{C}$. Three individual qPCR runs were conducted for each replicate. Intermittently occurring gene copy numbers that were found in negative controls were subtracted from the respective sample.

\section{Fluorescent in situ hybridization and confocal laser scanning microscopy}

In-tube fluorescent in situ hybridization (FISH) technique, followed by visualization with confocal laser scanning microscopy (CLSM), was performed to observe the colonization patterns and penetration spots of seed-associated bacteria and fungi. Seeds were fixed with $4 \%$ paraformaldehyde/phosphate-buffered saline at $4{ }^{\circ} \mathrm{C}$ over-night prior to FISH application according to the protocol of Cardinale et al. [34]. To stain the overall bacterial community, Cy3-labeled EUB338MIX [35] was used and in order to contrast fungal structures from plant cell walls; FISH samples were treated with Calcofluor White.

\section{Results}

Visualization of microbial communities and their abundance in alpine plant seeds

Seed morphology and size of the eight alpine plants investigated were highly variable, specifically adapted to their mode of dispersal. Seed size ranged from $0.7 \mathrm{~mm}$ for G. germanica seeds up to $6.5 \mathrm{~mm}$ for A. major seeds (Fig. 1a). We used different observation methods to explore microbial colonization patterns on seeds. Scanning electron microscopy was applied to monitor seed surfaces for microbial colonization; here, only few epiphytes were detected. Among them, fungal structures were more frequent than bacterial ones (results not shown). In addition, CLSM in combination with specific FISH probes allows to localize endophytes in different subcompartments of the seeds. Visualization was feasible for P. palustris and G. asclepiadea seeds (Fig. 1b). We found fungal structures more frequently than bacterial ones, and especially, the surface of $P$. palustris was covered with fungal hyphae. Comparably less Cy3-labeled bacteria were visualized colonizing seeds epi- and endophytically. Unfortunately, high autofluorescence of host tissues impeded imaging of microbiota in the seeds of the remaining plant genotypes.

In contrast, quantification via $\mathrm{qPCR}$ resulted in high microbial abundances in all seeds investigated, amounting for $2.8 \times 10^{11}, 3.09 \times 10^{9}$, and $4.2 \times 10^{11}$ mean gene copy numbers per gram seeds for bacteria, archaea, and fungi, respectively (Fig. 2). Significant differences in microbial 


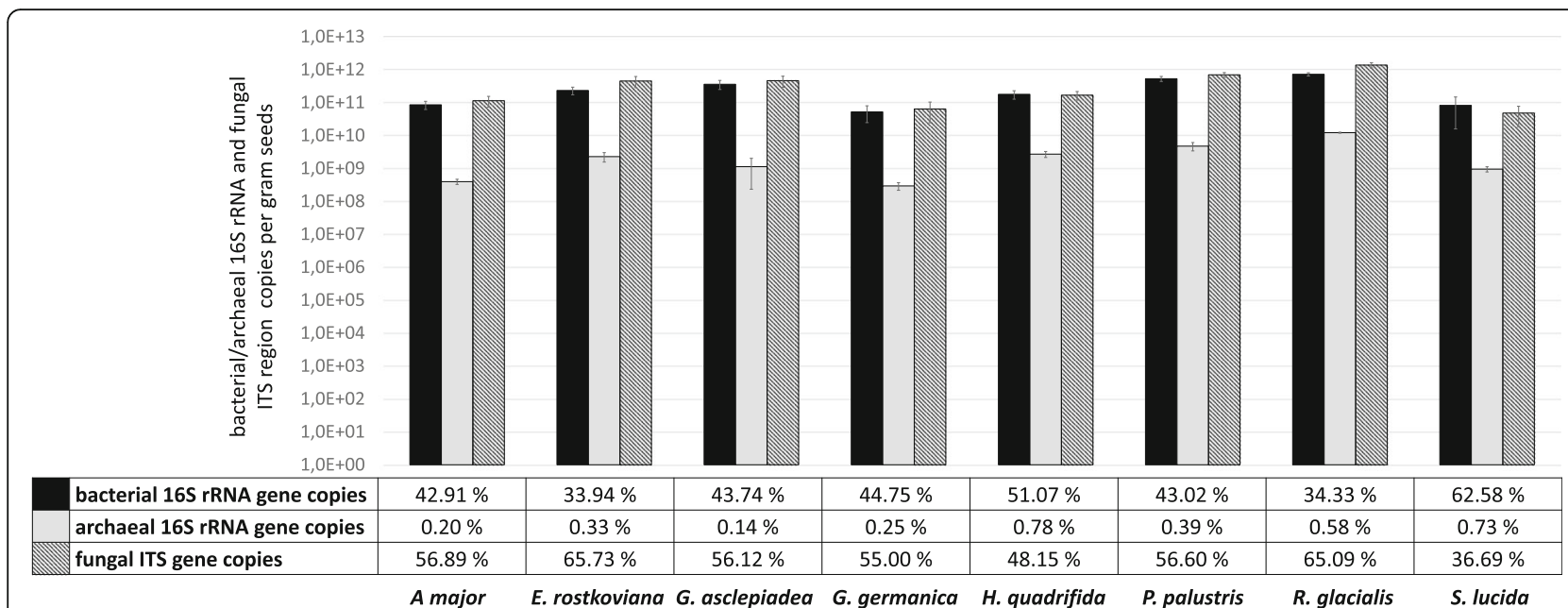

Fig. 2 Microbial gene copy numbers in alpine plant seeds determined by qPCR. Values are given by primers targeting bacterial and archaeal 16S rRNA gene and fungal ITS region in seeds of the eight different alpine plants. Gene copy numbers are calculated per gram seeds used for the microbiome analysis. The table describes the prokaryote to eukaryote ratio within the total microbial gene copies detected in the seeds of the respective plant genotype. Total microbial gene copies can be looked up in Additional file 1: Table S1

abundance were observed between the eight plant genotypes, whereas comparing fruit morphology (capsule or achene) or life cycle of the plant (annual or perennial) resulted in no statistical significance (Additional file 1: Table S1). This holds true both for the number of total microbial gene copies and for bacteria, archaea, and fungi calculated separately. The total microbial gene copies per plant genotype, consisting of bacteria, archaea, and fungi, ranged from $1.16 \times 10^{11}$ gene copies in G. germanica seeds to $2.10 \times 10^{12}$ gene copies in $R$. glacialis seeds. However, calculating the prokaryote to eukaryote ratio, indicated by percent values in Fig. 2, resulted in high similarities between the different plant genotypes. Fungal ITS gene copies slightly prevailed over bacterial and archaeal 16S rRNA gene copies, except for H. quadrifida and S. lucida seeds. Archaeal gene copies were detected in all replicates; however, less than $1 \%$ out of total microbial genes per plant genotype were archaeal. This ratio was found to be consistent over the sample collection, and no mutual exclusions between the three taxonomic groups were observed: seeds with high bacterial gene copies ( $R$. glacialis, P. palustris, G. asclepiadea, and E. rostkoviana) showed high copy numbers of archaeal and fungal genes as well, while seeds with less bacterial copy numbers (A. major, G. germanica, and S. lucida) exhibit also less archaeal and fungal gene copies.

With respect to both the microscopic and the quantitative evaluations, the majority of seed-associated microorganisms is most probably localized inside the seeds.

\section{Unique microbial composition associated within alpine plant seeds}

After quality-filtering and removing chimeric sequences, the amplicon dataset with the $16 \mathrm{~S}$ rRNA gene fragments from alpine plant seeds contained 4, 703,620 paired reads. Chloroplast and mitochondrial sequences were removed, and 1,769,793 sequences remained in the dataset that were assigned to a total of 11,842 operational taxonomic units (OTUs). The quality-filtered and chimera-checked ITS dataset contained 10,443,899 paired reads that were assigned to 3943 fungal OTUs. OTU tables were rarefied to 1739 bacterial and archaeal sequences and 5807 fungal sequences per sample, according to the samples with lowest amount of sequences.

The taxonomic assignment of 11,844 bacterial OTUs revealed 36 phyla, among them Proteobacteria were predominant in the dataset with $88.9 \%$, followed by Actinobacteria (3.3\%) and Bacteroidetes (2.2\%). $\gamma$ Proteobacteria was the most abundant class received, amounting to $48.7 \%$ relative abundance and represented by 83 genera. $\alpha$-Proteobacteria showed the highest diversity, being represented by 395 genera and amounting to $34.4 \%$ relative abundance. Actinobacteria and Bacteroidetes were represented by 200 and 68 genera, respectively. Firmicutes (141 genera), Acidobacteria (51 genera), Chloroflexi (45 genera), Planctomycetes (38 genera), Verrucomicrobia (26 genera), and Cyanobacteria (21 genera) showed each less than $1 \%$ abundance in the whole dataset. The remaining and less represented taxa are not described here.

Archaeal taxonomy was assigned to 32 OTUs and represented $0.05 \%$ of the $16 \mathrm{~S}$ rRNA gene sequences. Archaea were mainly represented by Thaumarchaeota (98.3\% rel. abundance of all archaeal sequences) with three genera of the Soil Crenarchaeotic Group and Nitrosphaera. Euryarchaeota were less represented, 
amounting to $1.7 \%$ of archaeal community but were more diverse, consisting of the genera Haladaptatus, Methanobacterium, Methanobrevibacter, Natronorubrum, Methanosphaera, and one not further assigned genus of Halobacteriaceae.

The ITS amplicon library was assigned to 3945 fungal OTUs. Most abundant OTUs included Ascomycota with 74.2\% relative abundance and 274 genera and Basidiomycota with 25.8\% abundance and 119 genera. Among Ascomycota, the majority of OTUs were assigned to Dothideomycetes (50.5\% abundance and 93 genera), Sordariomycetes (1.3\% and 72 genera), Leotiomycetes (5.9\% and 48 genera), and Eurotiomycetes (2.1\% and 16 genera). The most abundant class within Basidiomycota was Tremellomycetes (23.0\%), although poorly diverse with only 19 genera. Microbotryomycetes $(2.3 \%$ and 11 genera) and Agaricomycetes (0.3\% and 77 genera) represented the remaining Basidiomycota. Chytridiomycota (0.04\% and three genera) and Glomeromycota $(0.002 \%)$, Rozellomycota (0.001\%) and Zygomycota (0.0005\%), each represented by one genus, were much less abundant.

The composition of bacterial, archaeal, and fungal genera that were present in each replicate of a sample is visualized in Additional file 1: Figure S1. For bacteria and fungi, a threshold of $0.01 \%$ abundance was set. As most archaea were present with less than $0.01 \%$ in the $16 \mathrm{~S}$ rRNA gene library, no threshold was set for archaeal composition to be included in Additional file 2: Figure S2. Those highly diversified microbiomes included 70 bacterial, 10 archaeal, and 58 fugal genera. Among them, some highly abundant genera were shared between the seed core microbiomes of all plant genotypes, but the relative abundance of those showed high variations. Sphingomonas, Pseudomonas, Tatumella, or Pantoea, known for their ubiquitous association with plants, were present in all seed core microbiomes (Additional file 1: Figure S1A); the same was true for three different, but not further assigned archaeal taxa of Soil Crenarchaeotic Group (Additional file 1: Figure S1B). Fungal composition showed some consistencies among high abundant Cryptococcus, Cladosporium, or Davidiella (Additional file 1: Figure S1C). The mean relative abundance of all bacteria and archaea and all fungi in the whole dataset with at least $0.01 \%$ abundance are listed in Additional file 1: Table S2 and S3, respectively.

\section{Identification of the main drivers of the native seed microbiome}

The bacterial and fungal diversity within the alpine plant was assessed by Shannon diversity index, and significant differences $(p<0.05)$ between plant genotypes were calculated using the parametric twosample $t$ test at the greatest rarefaction depth. The samples were either grouped by plant genotype, the life cycle, or the fruit type, in order to identify dependencies of microbial diversity on either category (Additional file 2: Figure S2 and Table S4). When the samples were grouped by their plant genotype, values for bacterial diversity ranged from E. rostkoviana seeds (5.09) to $R$. glacialis seeds (2.4). Diversity of $E$. rostkoviana seed microbiome was found to be significantly higher than $R$. glacialis and G. germanica seed microbiomes. Significant differences in fungal diversity were observed between most diverse G. asclepiadea seeds (5.09) and $R$. glacialis, P. palustris, G. germanica, E. rostkoviana, and $H$. quadrifida seeds. H. quadrifida seed mycobiome was furthermore significantly more diverse than the one of G. germanica. A. major's seed mycobiome was significantly more diverse than $R$. glacialis'. The mycobiome diversity is therefore suggested to be more dependent on the plant genotype than the bacterial diversity. When the samples were grouped by their life cycle, no significant differences in diversity were observed for the bacterial microbiota, while the mycobiome of perennial plant seeds $(4.53 \pm 0.05)$ was significantly more diverse than the mycobiome $(3.12 \pm 0.05)$ of annuals. No significant difference in Shannon diversity for both bacteria and fungi was observed when the samples were grouped by their fruit type.

In order to evaluate the main driver of the seed microbiome composition, beta-diversity analysis was conducted using PCoA (Fig. 3) in combination with ANOSIM (Additional file 2: Table S5). Among the selected categorical variables "plant genotype," "life cycle," and "fruit type," the plant genotype was found be the main driver of the microbial composition of alpine plant seeds. This applies both for bacteria $(R=0.509 ; p=0.001)$ and fungi $(R=0.612 ; p=0.001)$. The bacterial composition seems to be further dependent on the plant's life cycle $(R=0.198 ; p=$ 0.004 ), either annual or perennial, while the life cycle dependency was even higher for fungi $(R=$ $0.395 ; p=0.001)$. The fruit type (capsule or achene) had no impact on the microbial composition giving the following ANOSIM values: $R=0.058 ; p=0.23$ for bacteria and $R=-0.029 ; p=0.584$ for fungi. The ANOSIM pairwise option was applied to compare the seed microbiomes of all plant genotypes; among the 28 combinations, 18 and 22 were significantly different for the bacterial and the fungal community, respectively (Additional file 2: Table S6). These results indicate that the fungal community has a higher plant genotype specificity than the bacterial community. However, it cannot be argued that two plant genotypes harbor similar microbial communities, as for all combinations either the bacterial or the fungal microbiome was significantly different. 


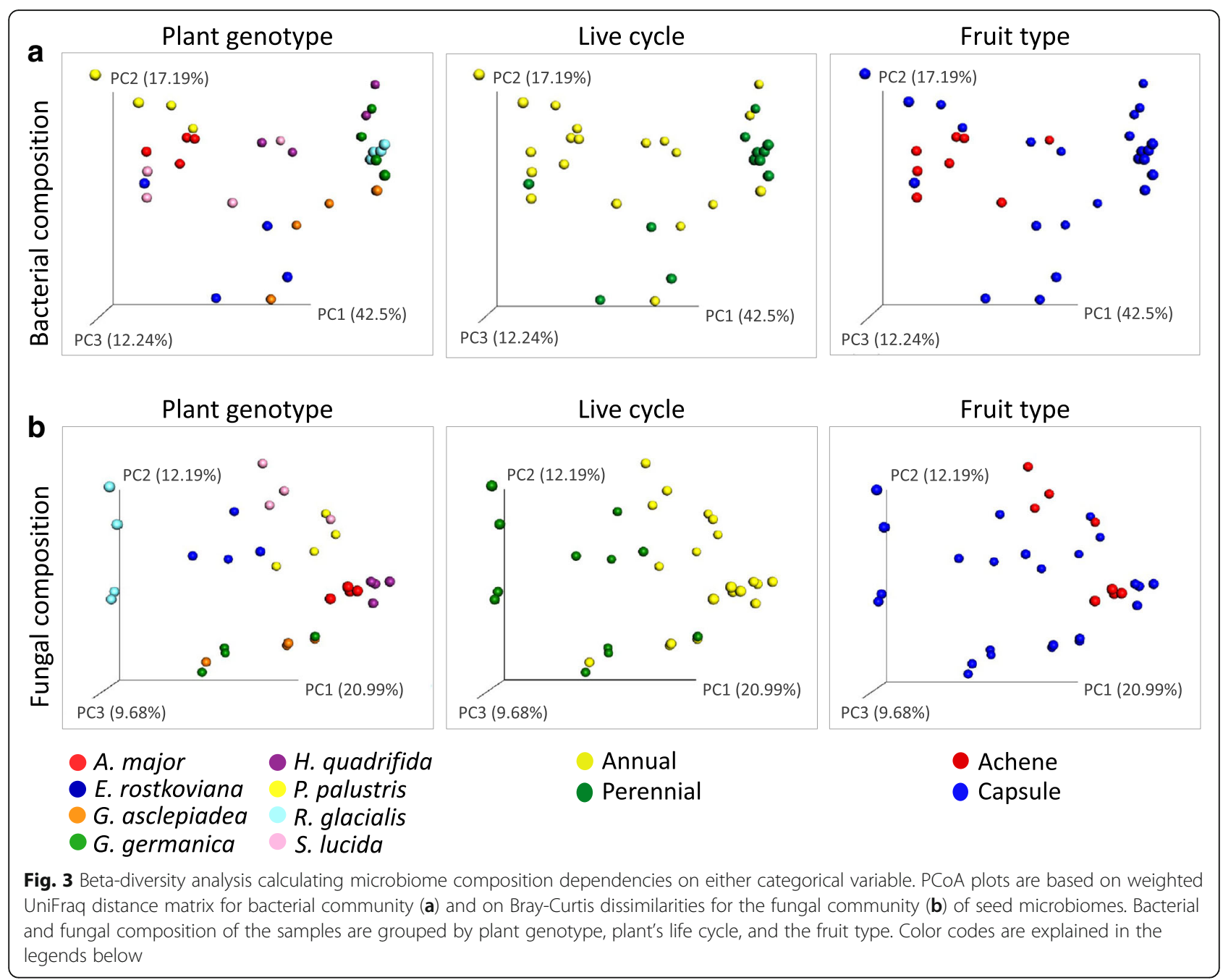

The limited seed core microbiome validates the unique signature of the plant genotype

In order to evaluate the dissimilarities between the seed microbiomes of the eight plant genotypes, the amount of shared OTUs was quantified. Only eleven out of 11,810 bacterial OTUs and only five out of 3945 fungal OTUs were present in all seeds (Table 1). This amounts to a percentage of $0.09 \%$ shared bacterial OTUs and $0.13 \%$ shared fungal OTUs, assigning bacteria a slight, but even higher plant genotype-dependent composition than fungi. Those bacterial and fungal OTUs represented the exceedingly undersized core microbiome shared by all alpine plant seeds. Regarding archaea, not a single OTU out of 32 OTUs was shared. A genotype dependency of archaea is therefore highly assumed as well; however, a number of 32 OTUs is too low to give a clear assessment. The abundances of the shared bacterial and fungal OTUs varied considerably between the samples; hence, these shared OTUs are not coincidently highly abundant in all seeds.
The percentage amount of OTUs occurring exclusively in the core microbiomes of either plant genotype, while being absent in the core microbiomes of the other plants, was furthermore assessed (Table 1). Here, the core microbiome refers to OTUs that are present in all replicates of a plant species. The calculation revealed a highly specific seed microbiome for each plant genotype, reaching from $65.7 \%$ unique OTUs in E. rostkoviana seeds to $5.2 \%$ unique OTUs in $S$. lucida seeds. Unique fungal OTUs per plant genotype were even more frequent, reaching from $76.1 \%$ unique OTUs in G. asclepiadea seeds to $12.7 \%$ unique OTUs in $P$. palustris seeds. Those results further promote the clear plant genotype dependency of the seed microbiomes.

\section{Contrasting interconnections of bacteria, archaea, and fungi within the microbial network}

In order to illustrate general co-occurrence patterns of the seed microbiota across all plant genotypes, a network analysis was performed (Fig. 4). The network, 
Table 1 Abundance of core OTUs in all seeds and percentage of OTUs exclusive for the core microbiomes of each plant genotype

\begin{tabular}{|c|c|c|c|c|c|c|c|c|c|}
\hline & & $\begin{array}{l}\text { A. } \\
\text { major }\end{array}$ & $\begin{array}{l}\text { E. } \\
\text { rostkoviana }\end{array}$ & $\begin{array}{l}\text { G. } \\
\text { asclepiadea }\end{array}$ & $\begin{array}{l}\text { G. } \\
\text { germanica }\end{array}$ & $\begin{array}{l}\text { H. } \\
\text { quadrifida }\end{array}$ & $\begin{array}{l}P \text {. } \\
\text { palustris }\end{array}$ & $\begin{array}{l}\text { R. } \\
\text { glacialis }\end{array}$ & $\begin{array}{l}\text { S. } \\
\text { lucida }\end{array}$ \\
\hline \multirow{11}{*}{$\begin{array}{l}\text { Bacterial core OTUs shared by all } \\
\text { seeds* }\end{array}$} & Tatumella sp. & 0.21 & 1.94 & 6.06 & 24.60 & 0.95 & 0.69 & 75.84 & 2.42 \\
\hline & Pseudomonas sp. & 13.84 & 5.39 & 29.51 & 0.32 & 32.27 & 5.40 & 0.06 & 7.63 \\
\hline & Pseudomonas putida & 0.17 & 0.26 & 1.73 & 27.40 & 9.48 & 0.14 & 0.24 & 0.65 \\
\hline & $\begin{array}{l}\text { Pseudomonas } \\
\text { fluorescens }\end{array}$ & 0.41 & 0.47 & 2.02 & 0.49 & 12.43 & 0.34 & 0.62 & 2.64 \\
\hline & Serratia liquefaciens & 0.75 & 1.15 & 0.77 & 0.37 & 1.11 & 0.72 & 1.35 & 4.17 \\
\hline & Burkholderia sp. & 0.16 & 0.28 & 0.30 & 0.10 & 0.35 & 0.34 & 0.73 & 2.80 \\
\hline & Bacillus subtilis & 0.20 & 0.19 & 0.23 & 0.08 & 0.34 & 0.28 & 0.70 & 0.13 \\
\hline & Pseudomonas protegens & 0.13 & 0.26 & 0.16 & 0.17 & 0.62 & 0.08 & 0.12 & 0.21 \\
\hline & Curvibacter gracilis & 0.05 & 0.07 & 0.09 & 0.03 & 0.14 & 0.10 & 0.17 & 0.61 \\
\hline & Pelomonas sp. & 0.02 & 0.04 & 0.04 & 0.01 & 0.06 & 0.05 & 0.15 & 0.64 \\
\hline & $\begin{array}{l}\text { Acinetobacter } \\
\text { calcoaceticus }\end{array}$ & 0.04 & 0.07 & 0.03 & 0.02 & 0.05 & 0.04 & 0.05 & 0.09 \\
\hline \multicolumn{2}{|c|}{$\begin{array}{l}\text { Percentage of bacterial OTUs unique for the plant's core } \\
\text { microbiome** }\end{array}$} & 44.1 & 65.7 & 38.0 & 31.3 & 11.4 & 21.7 & 15.4 & 5.2 \\
\hline \multirow[t]{5}{*}{$\begin{array}{l}\text { Fungal core OTUs shared by all } \\
\text { seeds* }\end{array}$} & $\begin{array}{l}\text { Cladosporium } \\
\text { cladosporioides }\end{array}$ & 7.31 & 27.37 & 14.55 & 46.33 & 2.41 & 3.59 & 25.77 & 6.53 \\
\hline & Cryptococcus victoriae & 15.14 & 1.78 & 8.05 & 4.64 & 28.21 & 14.34 & 0.02 & 8.03 \\
\hline & Davidiella tassiana & 6.40 & 7.14 & 14.79 & 15.52 & 12.34 & 14.54 & 1.18 & 5.07 \\
\hline & $\begin{array}{l}\text { Boeremia exigua var. } \\
\text { populi }\end{array}$ & 0.46 & 10.95 & 3.11 & 0.14 & 1.98 & 29.00 & 0.03 & 19.77 \\
\hline & Epicoccum nigrum & 4.94 & 8.76 & 1.45 & 2.20 & 6.53 & 1.16 & 1.57 & 11.40 \\
\hline \multicolumn{2}{|c|}{$\begin{array}{l}\text { Percentage of fungal OTUs unique for the plant's core } \\
\text { microbiome }\end{array}$} & 33.1 & 35.7 & 76.1 & 12.5 & 31.0 & 12.7 & 23.5 & 26.5 \\
\hline
\end{tabular}

*Numbers denote for relative abundance (\%) in seeds of each plant genotype. Taxonomy was assigned at species level to core OTUs using NCBI BLAST alignment tool

**Percentage of OTUs occurring in all replicates of the respective plant species, while being absent in the core microbiomes of all other plant species

showing significant co-occurrence and mutual exclusion patterns of the seed-associated microbiota, consists of 223 nodes, a characteristic path length of 4.392, and a network density with 0.044 . The vast majority of bacteria represent a very dense and highly interactive part of the network where exclusively positive interactions occur. The remaining bacteria, partially distantly located to this dense part, show only positive interactions as well. Archaea from the genus Nitrososphaera form a distinct and positive interacting cluster with some bacteria that are described for plant-beneficial properties. This distinct cluster is connected to the main network by a Comamonadaceae taxon. The entirety of negative interactions, i.e., mutual exclusions, was observed for fungi, located outside of the dense part of the bacterial network.

\section{Discussion}

The results of this study confirm our hypothesis that seeds of native plants harbor a more specific microbiota than already discovered for crop plants. The key findings of this study were (i) the unexpected high microbial abundances mainly driven by the plant genotype, (ii) the consistent eukaryote to prokaryote ratio across all seeds investigated, (iii) the high degree of plant specificity shown for the entire microbiome, (iv) the first identification of plant-specific seed-borne archaea, (v) an exceptionally small core microbiome although all plants grow together for centuries in the same soil and under the same environmental conditions, and (vi) the network of bacteria and archaea, which was in contrast to the negatively interacting fungal network.

The alpine plants studied showed a unique degree of plant specificity compared to the present literature [36-38]. Differences between seed microbiomes of the plant genotypes were found in terms of bacterial and fungal composition, abundance, and diversity. Inter-kingdom symbiosis was genotype-specific as well, as seeds with high bacterial gene copy numbers also showed high copy numbers of archaea and fungi and vice versa. The seeds share an exceedingly undersized core microbiome where only 11 out of 11 , 810 bacterial OTUs, only five out of 3945 fungal OTUs, and not a single OTU out of 32 archaeal OTUs were shared. The five fungal OTUs, which form the core, are classified as black fungi [39] able to persist ecological 


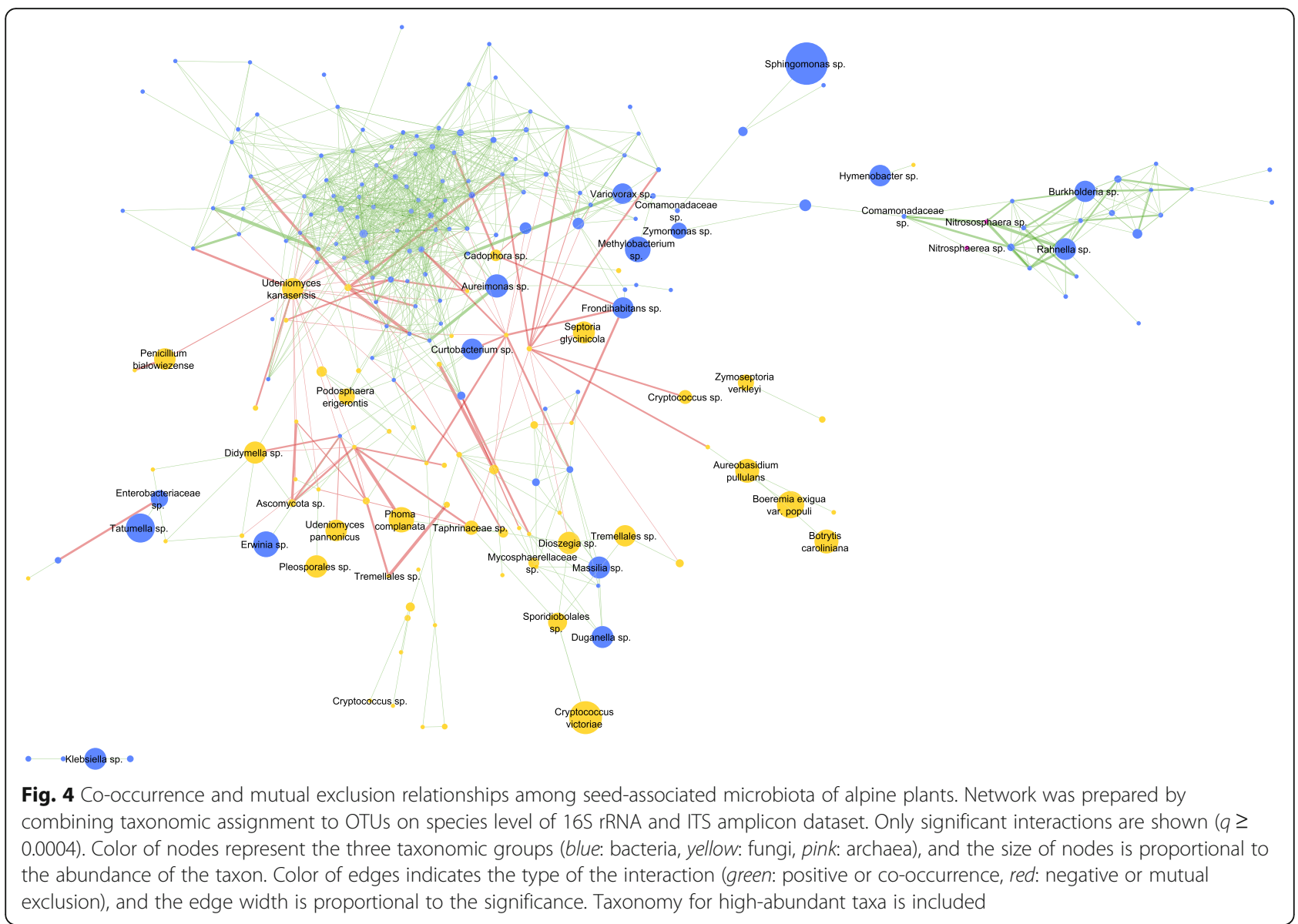

harshness and even to convert radiation into metabolic activity [40]. Rezki et al. [41] recently described an even higher degree of individual-specific microbiota for radish seeds; only three bacterial and 19 fungal OTUs were shared. However, those OTUs covered $70 \%$ and $87 \%$ of all bacterial and fungal reads within the individual plants. Reduced diversity and low evenness might therefore be suggested for crop plants, in comparison with the alpine plants. Here, the core OTUs represented an average of $3 \%$ and $10 \%$ of all bacterial and fungal reads, respectively. The amount of OTUs specific for each plant genotype was furthermore substantial, reaching up to $65.7 \%$ for bacteria in E. rostkoviana seeds and $76.1 \%$ for fungi in G. asclepiadea seeds. However, direct comparison to [41] is limited as $\operatorname{gyr} B$ instead of $16 \mathrm{~S}$ rRNA was selected as bacterial marker gene. Seeds of $R$. glacialis were found most unique, probably caused by specific, antimicrobial secondary metabolites [42]. Their microbial diversity was significantly lower, but the abundance was significantly higher compared to the other samples. In addition to the plant genotype, plant's life cycle was found to have an impact on the microbiome composition, where seed microbiota of perennial plants differed significantly from seeds of annual plants. This can be explained by the possibility to accumulate microbial diversity protecting the plants also during winter time. By selecting plants with two different fruit types, capsules and achenes, we aimed to specify the influence of the surrounding environment on seed microbiomes, which was found surprisingly to be not significant. This indicates that the airborne contribution to the seed microbiome is negligible. Significant genotype and life cycle dependency of the seedassociated microbiota was obvious, although we decided not to distinguish between seed endo- and epiphytes and considered both as an entire community of the alpine plant seeds. However, our microscopic observations showed that seed surfaces were not or less colonized by microbes. Therefore, we promote the recent suggestion by Nelson [8] that the epiphytic seed community is less insignificant than previously expected.

According to present literature, a plant-pathogenic potential can be assigned to the majority of highly abundant seed-associated fungi (e.g., Botrytis, Alternaria, Phoma, Didymella, Davidiella [43-46]) while the abundance of fungal taxa with described parasitism towards other fungi was high as well (e.g., Cryptococcus, Dioszegia [47]). However, all seeds were sampled from healthy 
plant populations, persisting under the given conditions for many growing seasons; germination ability is therefore highly assumed. Resilience towards emerging pathogens and adverse environmental conditions is probably supported by a highly abundant and competitive mycobiome. The inter-kingdom co-occurrence network illustrates the antagonistic features of the mycobiome; exclusively all mutual exclusions were observed for fungi. This stands in vast contrast to the positively interacting bacterial network, indicating synergism and stability. Competition for resources and space within the seed mycobiome has already been proposed by Rezki et al. [48], where the invasion of a fungal plant pathogen altered the fungal, but not the bacterial seed community, and Johnston-Monje and Raizada [49] suggested stability of bacteria, based on conserved patterns of bacterial endophytes in Zea seeds across boundaries of evolution. Among archaea, two OTUs of Nitrososphaera were present in the significant inter-kingdom network, positively interacting with bacteria. Beyond that, archaea were detected in all seeds investigated. We therefore assume an important ecological function of this domain for plant health and development. The performance of co-occurrence networks can be interfered by the input matrix when metacommunities from different habitats are combined, which in such cases can result in cooccurrence due to the habitat sampled rather than direct biological interactions (habitat filtering effect) [50]. Simulation models and algorithms described in literature $[50,51]$ can remedy that issue, which however would require a greater sample size than the available in the present study. The sampling for the present study was conditioned by the number of plants per genotype grown on the alpine meadow. However, the sample size was still sufficient for the present network where statistical tests, reported to give highest specificity and sensitivity, were applied [51]. Interpretability of the present network inferring putative microbial interactions in alpine plant seeds is therefore feasible when keeping potential interferences in mind. Altogether, our results indicate specified functions within the whole microbial network: bacteria and archaea strengthen the beneficial interplay within the holobiont, while fungi are responsible for degradation of the organic matter, e.g., seed shell, and may be to condition and train the prokaryotic microbiome through their antagonistic pressure.

A comparison of the microbiota of native and crop seeds confirmed our hypothesis that seeds of native plants harbor a more specific and differentially composed microbiota in comparison with cultivated plants that were investigated so far. Links et al. [52] compared seed microbiomes of Brassica and Triticum crops and found a hundredfold higher amount of shared OTUs (578 out of 5477 OTUs) compared to alpine seeds. The contrast is increased by the fact that Brassica and Triticum seeds were originated from different locations, but showed still higher similarity than the seeds of alpine plants, sampled on less than $20,000 \mathrm{~m}^{2}$. Truyens et al. [5] reviewed that Bacillus, Pseudomonas, Paenibacillus, Micrococcus, Staphylococcus, Pantoea, and Acinetobacter, in ascending order, are the most common bacteria within seeds of very different crop species. This is only partially consistent with our results. Alpine plant seeds are dominated by Pseudomonas, Sphingomonas, Tatumella, Methylobacterium, and Pantoea. The abundance of Bacillus, Acinetobacter, and especially Paenibacillus, Staphylococcus, and Micrococcus was very low. Differences to comparable studies on crop seeds $[17,22,49,52-54]$ were also observed on higher taxonomic levels: alpine plant seeds showed higher abundance of $\alpha$-Proteobacteria but far lower abundance of Actinobacteria and Firmicutes.

Until now, mainly crop seeds were studied. What can we learn from the native seeds about a healthy seed microbiome? A healthy seed microbiome (i) is diverse, rich, and evenly structured; (ii) contains bacteria, archaea, and fungi; (iii) contains microorganisms known for beneficial as well as for pathogenic interaction; and is (iv) highly specific. We found substantial differences to the microbiomes of crop seeds; the same has already been reported for the rhizosphere microbiome [19]. This is not surprising because cultivation pressure on seeds started around 8000 years ago and included, among others, the two major alterations on seed morphology: increased grain size and non-shattered seeds [55], where the latter predicated successful seed dispersal on human activity [56]. Today, seed treatments focus on uniform, clean, and pathogen-free seeds that are almost entirely produced commercially and traded globally [18]. In contrast, nature created a rich diversity of seed and fruit systems, with their own genotype-specific microbiomes. Figure 1 illustrates the morphological diversity of seeds and associated microbiota of the alpine plants investigated. Recent agriculture leads to a global landscape highly dominated by only few crop plants with desired characteristics. An enormous amount of $70 \%$ of wild relatives of modern crop plants are threatened with extinction [57]; consequentially, also their native microbiota with all their functional and metabolic skills are at risk of getting lost. For that reason, Berg and Raaijmakers [18] recently proposed international seed banks like Svalbard Global Seed Vault and Millennium Seed Bank to include conservation strategies for seed-associated microbiota. Based on the seed microbiota of wild ancestors or natural plants, microbial communities could be reconstructed with the ultimate goal to improve resilience of modern crops and reduce the amount of required pesticides. 


\section{Conclusion}

Undisturbed environments provide the best settings to explain indigenous plant-microbe interactions. Under such conditions, in a protected Alpine meadow, we found highly diversified and abundant seed microbiomes consisting of bacteria, archaea, and fungi. Moreover, despite growing together in the same soil, we found a higher degree of plant specificity than already discovered for crop seeds. All results underline the importance of plant-specific seed microbiota to ensure best-matching microbial symbionts for the next generation. However, network analysis captured consistent patterns of cooccurrence between bacteria and archaea in contrast to exclusion within the fungal community across all plant genotypes. This outlines the importance of crosskingdom microbial interactions. We suggest that diversity associated with seeds may contribute to maintain soil microbial diversity, with importance for plasticity of the whole ecosystem. This knowledge can be translated into a better understanding of disease outbreaks and could be used for the production of resilient, healthy, and high-quality crop seeds.

\section{Additional files}

Additional file 1: Abundance and composition of seed microbiota. Table S1: Mean microbial gene copy numbers in the seeds of different plant genotypes quantified by qPCR. Figure S1: Microbial composition of the seed core microbiomes of each plant genotype. (A) shows bacterial, (B) archaeal, and (C) fungal composition. Only bacteria and fungi occurring with at least $0.01 \%$ relative abundance in the whole dataset are shown. For low abundant archaea, no threshold was set to be included in the figure. Taxa not assigned to genus level are labeled with "sp." after the lowest assignable taxonomic description. Table S2: Composition of the bacterial/archaeal microbiome with at least $0.1 \%$ abundance. Table S3: Composition of the fungal microbiome with at least $0.1 \%$ abundance. (DOCX 197 kb)

Additional file 2: Comparison of microbial diversity and composition between alpine seeds investigated. Figure S2: Comparison of bacterial and fungal diversity within alpine plant seeds. Shannon diversity indices were compared by grouping the samples according to their plant genotype (A), the life cycle of the plant (B), which is either annual or perennial, and the fruit type $(C)$, either achene or capsule. Colors of the grouping variables are shown on either right. Calculated values and standard deviations can be looked up in Table S4. Table S4: Shannon diversity indices of seed samples grouped by plant genotype, life cycle and fruit type. Table S5: ANOSIM results of community composition dependency for bacteria and fungi on the three categorical variables. Table S6: Pairwise ANOSIM results comparing differences in bacterial and fungal community composition between the seeds of the eight plant genotypes. (DOCX $401 \mathrm{~kb}$ )

\section{Acknowledgements}

We thank Barbara Fetz for technical assistance in conducting qPCR and Martin Grube (all Graz, Austria) for stimulating discussions.

\section{Authors' contributions}

$\mathrm{CB}$ and $\mathrm{GB}$ contributed to the study design. $\mathrm{CB}, \mathrm{GB}$, and $\mathrm{BW}$ carried out the sampling and sample processing. BW, HM, and TC carried out the data analysis. BW and GB wrote the manuscript. All authors improved and approved the final manuscript.
Funding

Not applicable

\section{Availability of data and materials}

The raw sequence data for the $16 \mathrm{~S}$ rRNA gene and the ITS region are available from the European Nucleotide Archive (ENA) at study accession number PRJEB28955.

Ethics approval and consent to participate

Not applicable

\section{Consent for publication}

Not applicable

\section{Competing interests}

The authors declare that they have no competing interests.

\section{Author details}

${ }^{1}$ Institute of Environmental Biotechnology, Graz University of Technology, Petersgasse 12, 8010 Graz, Austria. ${ }^{2}$ Institute of Biology, Department of Plant Sciences, NAWI Graz, University of Graz, 8010 Graz, Austria.

Received: 2 April 2019 Accepted: 16 July 2019

Published online: 24 July 2019

\section{References}

1. Vandenkoornhuyse P, Quaiser A, Duhamel M, Le Van A, Dufresne A. The importance of the microbiome of the plant holobiont. New Phytol. 2015; 206:1196-206

2. Berg G, Rybakova D, Grube M, Köberl M. The plant microbiome explored: implications for experimental botany. J Exp Bot. 2016;67:995-1002.

3. Hardoim PR, van Overbeek LS, Berg G, Pirttilä AM, Compant S, Campisano A, et al. The hidden world within plants: ecological and evolutionary considerations for defining functioning of microbial endophytes. Microbiol Mol Biol Rev. 2015;79:293-320.

4. Berg G, Alavi M, Schmid M, Hartmann A. The rhizosphere as a reservoir for opportunistic human pathogenic bacteria. Mol Microb Ecol Rhizosph. 2013; 2:1209-16.

5. Truyens S, Weyens N, Cuypers A, Vangronsveld J. Bacterial seed endophytes: genera, vertical transmission and interaction with plants. Environ Microbiol Rep. 2015;7:40-50.

6. Sánchez-Cañizares C, Jorrín B, Poole PS, Tkacz A. Understanding the holobiont: the interdependence of plants and their microbiome. Curr Opin Microbiol. 2017:38:188-96.

7. Shade A, Jacques MA, Barret M. Ecological patterns of seed microbiome diversity, transmission, and assembly. Curr Opin Microbiol. 2017;37:15-22.

8. Nelson EB. The seed microbiome: origins, interactions, and impacts. Plant Soil. 2018;422:7-34.

9. Vujanovic V, Germida J. Seed endosymbiosis: a vital relationship in providing prenatal care to plants. Can J Plant Sci. 2017;97(6):972-81.

10. Shahzad R, Bilal S, Khan AL, Asaf S, Lee I-J. What is there in seeds? Vertically transmitted endophytic resources for sustainable improvement in plant growth. Front Plant Sci. 2018;9:1-10.

11. Taffner J, Erlacher A, Bragina A, Berg C, Moissl-Eichinger C, Berg G. What is the role of Archaea in plants? New insights from the vegetation of alpine bogs. mSphere. 2018;3:1-14.

12. Geisen $\mathrm{S}$, Kostenko $\mathrm{O}$, Cnossen $\mathrm{MC}$, ten Hooven $\mathrm{FC}$, Vreš $\mathrm{B}$, van der Putten $\mathrm{WH}$. Seed and root endophytic fungi in a range expanding and a related plant species. Front Microbiol. 2017:8:1-11.

13. Yang $\mathrm{H}, \mathrm{Ye} \mathrm{W}, \mathrm{Ma} J$, Zeng D, Rong Z, Xu M, et al. Endophytic fungal communities associated with field-grown soybean roots and seeds in the Huang-Huai region of China. PeerJ. 2018;6:e4713.

14. Schardl CL, Leuchtmann A, Spiering MJ. Symbioses of grasses with seedborne fungal endophytes. Annu Rev Plant Biol. 2004;55:315-40.

15. Rodriguez RJ, White Jr JF, Arnold AE, Redman RS. Fungal endophytes: diversity and functional roles. New Phytol. 2009;182:314-30.

16. Adam E, Bernhart M, Müller H, Winkler J, Berg G. The Cucurbita pepo seed microbiome: genotype-specific composition and implications for breeding. Plant Soil. 2018:422:35-49. 
17. Johnston-Monje D, Lundberg DS, Lazarovits G, Reis VM, Raizada MN Bacterial populations in juvenile maize rhizospheres originate from both seed and soil. Plant Soil. 2016;405:337-55.

18. Berg G, Raaijmakers JM. Saving seed microbiomes. ISME J. 2018;12:1167-70.

19. Germida J, Siciliano S. Taxonomic diversity of bacteria associated with the roots of modern, recent and ancient wheat cultivars. Biol Fertil Soils. 2001;33:410-5.

20. Pérez-Jaramillo JE, Mendes R, Raaijmakers JM. Impact of plant domestication on rhizosphere microbiome assembly and functions. Plant Mol Biol. 2016;90:635-44.

21. Pérez-Jaramillo JE, Carrión VJ, Bosse M, Ferrão LFV, de Hollander M, Garcia AAF, et al. Linking rhizosphere microbiome composition of wild and domesticated Phaseolus vulgaris to genotypic and root phenotypic traits. ISME J. 2017;11:2244-57.

22. Rybakova D, Mancinelli R, Wikström M, Birch-Jensen A-S, Postma J, Ehlers R$U$, et al. The structure of the Brassica napus seed microbiome is cultivardependent and affects the interactions of symbionts and pathogens. Microbiome. 2017;5:104.

23. Fenner M, Thompson K. The ecology of seeds. Cambridge: Cambridge University Press; 2005.

24. Bever JD, Mangan SA, Alexander HM. Maintenance of plant species diversity by pathogens. Annu Rev Ecol Evol Syst. 2015;46:305-25.

25. Dirnböck T, Dullinger S, Gottfried M, Grabherr G. Die Vegetation des Hochschwab (Steiermark) - Alpine und Subalpine Stufe. Mitt Naturwissen Vereine Stmk. 1999;129:111-251.

26. Radulović NS, Mladenović MZ, Dordević ND. Chemotypification of astrantia major L. (Apiaceae): essential-oil and lignan profiles of fruits. Chem Biodivers. 2012;9:1320-37.

27. Teixeira R, Silva LR. Bioactive compounds and in vitro biological activity of Euphrasia rostkoviana Hayne extracts. Ind Crops Prod. 2013;50:680-9.

28. Caporaso JG, Kuczynski J, Stombaugh J, Bittinger K, Bushman FD, Costello EK, et al. QIIME allows analysis of high-throughput community sequencing data. Nat Methods. 2010;7:335-6.

29. White TJ, Bruns T, Lee S, Taylor JW. Amplification and direct sequencing of fungal ribosomal RNA genes for phylogenetics. In: Innis MA, Gelfand DH, Sninsky JJ, White TJ, editors. PCR Protocols: A Guide to Methods and Applications, vol. 64. San Diego: Academic Press; 1990. p. 315-22.

30. Lundberg DS, Yourstone S, Mieczkowski P, Jones CD, Dangl JL. Practical innovations for high-throughput amplicon sequencing. Nat Methods. 2013; 10:999-1002.

31. Edgar RC. Search and clustering orders of magnitude faster than BLAST. Bioinformatics. 2010;26:2460-1.

32. Köberl M, Müller H, Ramadan EM, Berg G. Desert farming benefits from microbial potential in arid soils and promotes diversity and plant health. PLoS One. 2011;6:e24452

33. Probst AJ, Auerbach AK, Moissl-Eichinger C. Archaea on human skin. PLoS One. 2013;8:e65388.

34. Cardinale M, Viera de Castro J, Müller H, Berg G, Grube M. In situ analysis of the bacterial community associated with the reindeer lichen Cladonia arbuscula reveals predominance of Alphaproteobacteria. FEMS Microbiol Ecol. 2008;66:63-71

35. Daims H, Brühl A, Amann R, Schleifer KH, Wagner M. The domain-specific probe EUB338 is insufficient for the detection of all bacteria: development and evaluation of a more comprehensive probe set. Syst Appl Microbiol. 1999:22:434-44.

36. Berg G, Smalla K. Plant species and soil type cooperatively shape the structure and function of microbial communities in the rhizosphere. FEMS Microbiol Ecol. 2009;68:1-13.

37. Bulgarelli D, Garrido-Oter R, Münch PC, Weiman A, Dröge J, Pan Y, et al. Structure and function of the bacterial root microbiota in wild and domesticated barley. Cell Host Microbe. 2015;17:392-403.

38. Bulgarelli D, Schlaeppi K, Spaepen S, van Themaat EVL, Schulze-Lefert P. Structure and functions of the bacterial microbiota of plants. Annu Rev Plant Biol. 2013;64:807-38.

39. Diederich P. New or interesting lichenicolous fungi. 1. Species from Luxembourg. Mycotaxon. 1990;37:297-330.

40. Dadachova E, Bryan RA, Huang X, Moadel T, Schweitzer AD, Aisen P, et al. lonizing radiation changes the electronic properties of melanin and enhances the growth of melanized fungi. PLOS One. 2007;2.
41. Rezki S, Campion C, Simoneau P, Jacques M-A, Shade A, Barret M. Assembly of seed-associated microbial communities within and across successive plant generations. Plant Soil. 2018;422:67-79.

42. Compean K, Ynalvez R. Plant secondary metabolites and vertebrate herbivores.pdf. Reserach Journal of Medicinal Plant. 2014;8:204-13.

43. Dean R, Van Kan JAL, Pretorius ZA, Hammond-Kosack KE, Di Pietro A, Spanu $P D$, et al. The Top 10 fungal pathogens in molecular plant pathology. Mol Plant Pathol. 2012;13:414-30.

44. Tsuge T, Harimoto $Y$, Akimitsu K, Ohtani K, Kodama M, Akagi Y, et al. Hostselective toxins produced by the plant pathogenic fungus Alternaria alternata. FEMS Microbiol Rev. 2013;37:44-66.

45. Keinath AP. From native plants in central Europe to cultivated crops worldwide: the emergence of Didymella bryoniae as a cucurbit pathogen HortScience. 2011;46:532-5.

46. Thomma BPHJ, Van Esse HP, Crous PW, De WITPJGM. Cladosporium fulvum (syn. Passalora fulva), a highly specialized plant pathogen as a model for functional studies on plant pathogenic Mycosphaerellaceae. Mol Plant Pathol. 2005:6:379-93.

47. Sterkenburg E, Bahr A, Brandström Durling M, Clemmensen KE, Lindahl BD. Changes in fungal communities along a boreal forest soil fertility gradient. New Phytol. 2015;207:1145-58.

48. Rezki S, Campion C, lacomi-Vasilescu B, Preveaux A, Toualbia Y, Bonneau $\mathrm{S}$, et al. Differences in stability of seed-associated microbial assemblages in response to invasion by phytopathogenic microorganisms. PeerJ. 2016;4:e1923.

49. Johnston-Monje D, Raizada MN. Conservation and diversity of seed associated endophytes in Zea across boundaries of evolution, ethnography and ecology. PLoS One. 2011;6:e20396.

50. Brisson V, Schmidt J, Northen TR, Vogel JP, Gaudin A. A new method to correct for habitat filtering in microbial correlation networks. Front Microbiol. 2019;10:585.

51. Berry D, Widder S. Deciphering microbial interactions and detecting keystone species with co-occurrence networks. Front Microbiol. 2014;5:219.

52. Links MG, Demeke T, Gräfenhan T, Hill JE, Hemmingsen SM, Dumonceaux TJ. Simultaneous profiling of seed-associated bacteria and fungi reveals antagonistic interactions between microorganisms within a shared epiphytic microbiome on Triticum and Brassica seeds. New Phytol. 2014;202:542-53.

53. Lopez-Velasco G, Carder PA, Welbaum GE, Ponder MA. Diversity of the spinach (Spinacia oleracea) spermosphere and phyllosphere bacterial communities. FEMS Microbiol Lett. 2013;346:146-54.

54. Barret M, Briand $M$, Bonneau S, Préveaux A, Valière $S$, Bouchez $O$, et al. Emergence shapes the structure of the seed microbiota. Appl Environ Microbiol. 2015:81:1257-66.

55. Fuller DQ. Contrasting patterns in crop domestication and domestication rates: recent archaeobotanical insights from the old world. Ann Bot. 2007;100:903-24.

56. Purugganan MD, Fuller DQ. The nature of selection during plant domestication. Nature. 2009;457:843-8.

57. Castañeda-Álvarez NP, Khoury CK, Achicanoy HA, Bernau V, Dempewolf H, Eastwood RJ, et al. Global conservation priorities for crop wild relatives. Nat Plants. 2016;2:16022

\section{Publisher's Note}

Springer Nature remains neutral with regard to jurisdictional claims in published maps and institutional affiliations.

Ready to submit your research? Choose BMC and benefit from:

- fast, convenient online submission

- thorough peer review by experienced researchers in your field

- rapid publication on acceptance

- support for research data, including large and complex data types

- gold Open Access which fosters wider collaboration and increased citations

- maximum visibility for your research: over $100 \mathrm{M}$ website views per year

At $\mathrm{BMC}$, research is always in progress.

Learn more biomedcentral.com/submissions 